\title{
Non-English Majors' Writing Self-Efficacy and Attribution in Learning English as a Foreign Language
}

\author{
Zenan Chen $^{1}$ \\ ${ }^{1}$ School of English Studies, Shanghai International Studies University, Shanghai, China \\ Correspondence: Zenan Chen, School of English Studies, Shanghai International Studies University, Shanghai, \\ China. E-mail: 1505047200@qq.com
}

Received: January 20, 2021

Accepted: February 22, 2021

Online Published: February 26, 2021

doi:10.5539/ijel.v11n2p137

URL: https://doi.org/10.5539/ijel.v11n2p137

\begin{abstract}
This study examines the relationship between writing self-efficacy, attribution, and writing proficiency of college students in learning English as a foreign language (EFL) context. The scales of writing self-efficacy and attribution were administered to 142 Chinese first-grade non-English majors. Research findings showed that these EFL learners maintained a medium level of writing self-efficacy and tended to attribute their writing outcomes to internal causes. Independent sample t-test indicated that gender exerted no significant influence on EFL writing self-efficacy, and only the attribution cause luck significantly differed between boys and girls. Besides, high-achievers reported stronger writing self-efficacy and skill self-efficacy, while no significant difference in task self-efficacy was found between high-achievers and low-achievers. One-way ANOVA results revealed that regardless of writing level, students tended to attribute their writing success or failure to internal factors such as ability and effort, while low-achievers were also inclined to attribute externally. Pedagogical implications were also discussed.
\end{abstract}

Keywords: writing self-efficacy, writing attribution, non-English majors, English as a foreign language

\section{Introduction}

The acquisition of writing skills is a complex and multi-dimensional process involving many factors such as affect, motivation, cognition, personal effort, and external environment (Graham \& Harris, 1997; Zimmerman \& Katsinas, 1999; Hayes, 2000), thus rendering it a challenge for learners in any language (Anastasiou \& Michaël, 2013). What further makes writing a difficult and demanding task is the complexity and simultaneous coordination of many components, and such a task calls for multiple mental representations and cognitive processes constrained by limited working memory, attention, and usually time (McCutchen, 1996; Kellogg, 2008). As for Chinese EFL learners, writing may be deemed the most demanding among all language skills (Zhang \& Guo, 2012). As some studies have indicated, Chinese college students have a relatively low level of EFL writing competence, commonly lack motivation and confidence, or to some extent suffer psychological stress and apprehension in their writing practices (Yang, 2004; Zhang, 2005; Woodrow, 2011; Li \& Liu, 2013).

Given that learners' attitudes and affects play a vital part in writing (Faigley, Cherry, Jolliffe, \& Skinner, 1985), it is necessary to examine the relationship between writing proficiency and some motivational or emotional factors such as self-efficacy and attribution. According to Bandura's Social Cognitive Theory (1986), self-efficacy refers to individuals' perception of their abilities to perform a certain task (Woodrow, 2011), and writing self-efficacy is the writers' judgment of how well they can accomplish a writing task based on a comprehensive assessment of multiple factors, such as task difficulty and their writing levels (Sun \& Wang, 2020). Based on Weiner's Attribution Theory $(1972,1985)$, writing attribution can be defined as the writers' causal attribution of the success or failure of their writing activities.

The past three decades have seen a growing number of studies on the relationship between writing self-efficacy and writing outcomes (Zimmerman \& Bandura, 1994; Pajares, 2003, 2007; Anastasiou \& Michail, 2013; Bruning, Dempsy, Kauffman, McKim, \& Zumbrunn, 2013; Li, 2017). And it was also suggested that this relationship was associated with individual differences such as gender, grade level, and writing level (Pajares, Miller, \& Johnson, 1999; Pajares \& Valiante, 1999, 2001; Tang \& Xu, 2011) or some motivation constructs, especially anxiety, motivation and self-regulation (Pajares \& Johnson, 1996; Pajares, Britner, \& Valiante, 2000; Woodrow, 2011; Li \& Liu, 2013; Sun \& Wang, 2020). However, there has been little detailed investigation into 
the writing attribution of EFL learners in the tertiary education context, and the individual differences in EFL writing self-efficacy and attribution remain to be explored. The aim of the present study was threefold: (1) to present the status quo of EFL writing self-efficacy and attribution of Chinese first-grade non-English majors; (2) to examine the differences in writing self-efficacy and attribution between genders; (3) to explore the differences in writing self-efficacy and attribution among students at different writing levels.

\section{Literature Review}

\subsection{Writing Self-Efficacy in School Contexts}

A large number of studies have examined the relationship between writing self-efficacy and writing proficiency, consistently suggesting that they were positively related and the former was typically predictive of the latter (Zimmerman \& Bandura, 1994; Bruning \& Horn, 2000; Anastasiou \& Michail, 2013; Li, 2017; Daniels et al., 2019). For example, Anastasiou and Michail (2013) explored accordance or discordance between efficacy beliefs of low-literate adult students and their writing performance; Li (2017) examined the dynamic changes of EFL writing self-efficacy and writing performance of 330 Chinese non-English major students and justified writing self-efficacy as a significant source of effect on students' writing performance; Daniels et al. (2019) evaluated the effects of a writing self-efficacy intervention on the writing production of three middle school students and supported a relationship between writing self-efficacy and writing performance.

Furthermore, writing self-efficacy was reported to be linked with motivational factors that were themselves related to writing performance, such as anxiety (Pajares \& Johnson, 1996; Pajares \& Valiante, 1999, 2001; Woodrow, 2011; Li \& Liu, 2013; Sabti, Rashid, Nimehchisalem, \& Darmi, 2019), motivation (Pajares, 2003; Walker, Greene, \& Mansell, 2006; Zhang \& Guo, 2012), goal orientation (Schunk \& Swartz, 1993; Pajares et al., 2000; Li \& Xu, 2014; Teng, Sun, \& Xu, 2018) and self-regulation (Zimmerman \& Bandura, 1994; Bruning et al., 2013; Csizér \& Tankó, 2015; Han \& Hiver, 2018; Qiu \& Lee, 2020; Sun \& Wang, 2020; Teng \& Zhang, 2020). It was shown that self-efficacious writers were more confident and motivated (Zhang \& Guo, 2012), experienced less apprehension, possessed stronger effort, greater perseverance and resilience, and greater interest in and attention to writing (Pajares, 2003; Woodrows, 2011). Researchers have also proposed that holding task goals in writing was positively related to writing self-efficacy while holding performance-approach goals was negatively related (Pajares et al., 2000; Pajares \& Valiante, 2001; Pajares, 2003). Moreover, self-regulation was found to be positively related to writing self-efficacy (Sun \& Wang, 2020), which may be in part because learners developed self-efficacy beliefs as a result of how successful they perceived to be their self-regulatory strategies (Bandura \& Schunk, 1981).

Scholarly attention was also attracted to the influence of learners' individual differences on writing self-efficacy (e.g., gender, grade, ethnicity, writing level, socioeconomic status). Gender difference in writing self-efficacy has been a focus of writing research, but existing results have been inconsistent. Some studies have found that girls reported stronger confidence in their writing capabilities and thus scored better in writing performance than boys did (Pajares \& Valiante, 1999, 2001; Pajares et al., 1999), and these differences may diminish or even reverse as learners grew (Pajares, 2003). Pajares and Johnson (1996) observed that at Grade 9, girls reported lower writing self-efficacy than boys did, and Bruning and Horn (2000) found that girls experienced a drop in their academic motivation and perceptions of competence as they reached high school. However, some other studies reported no gender differences in writing self-efficacy (Shell, Colvin, \& Bruning, 1995; Tang \& Xu, 2011). As Sun and Wang (2020) pointed out, the contradicting effects of gender differences may stem from sample characteristics from various regions and deserve further investigations. In addition, grade differences in or developmental changes of writing self-efficacy have also received great attention, especially from elementary school to middle school. For example, Shell et al. (1995) measured the writing self-efficacy of students in three different grades and found no differences in their self-efficacy beliefs in grammar, usage, and composition skills, but their confidence in capability to accomplish writing tasks increased as they grew older. Pajares and Valiante (1999) suggested that students in Grade 6 reported higher writing self-efficacy than did their counterparts in Grade 7 and 8, and students in Grade 7 reported lower self-efficacy than did students in Grade 6 and 8, which exhibited a U-shape development of writing self-efficacy in school contexts. Compared with gender and grade, the other demographic characteristics and their relationship with writing self-efficacy have been less studied. It seems to me that the individual differences above are largely contextual and external factors, and therefore, are to some extent susceptible to the changes of environments or conditions in different studies. That may in part explain the inconsistency of some research findings.

\subsection{Attribution in School Contexts}

Attribution can be defined as "one's judgments about the causality of success or failure in achievement situation" 
(Shell et al., 1995, p. 386), and it has been a research focus in the field of social psychology. The first systematic attribution theory was propounded by American social psychologist Fritz Heider, and the most fundamental opinion he proposed was that the result of action could be felt to depend on two sets of conditions, i.e., factors within the person and factors within the environment (1958). Based on his predecessors' works and many empirical studies, Weiner $(1972,1985)$ revisited the relationship between causal attribution and achievement motivation and found that common people tended to attribute their success or failure of an action to six factors, namely ability, effort, perceived task difficulty, luck, physical or mental condition, external environment.

In the light of their characteristics, these six factors were subsumed under three dimensions: (1) stability, i.e., whether the cause of your success or failure is stable or not in nature. Ability and task difficulty are relatively stable, while other factors including effort, luck, physical \& mental condition, and external environment are unstable; (2) source of factors, i.e., whether your success or failure is attributed to internal or external factors. Ability, effort, and physical \& mental condition are internal factors, while the rest are external ones; (3) controllability, i.e., whether the cause can be controlled by oneself. Most of the factors are uncontrollable except effort (see Zhang, 2002, for more).

Compared with self-efficacy, attribution has been less studied in school contexts but its relationship with other motivational constructs or learning achievements has been widely discussed (Weiner, 1972, 1979, 1985; Wen \& Johnson, 1997; Qin, 2002; Zhang, 2002; Li, 2004; Luo \& Chen, 2013). Weiner (1972, 1985) examined the characteristics of attribution in the educational process and reported its close relation with achievement motivation, and Weiner (1979) found that achievement attribution was closely associated with learning outcomes. By way of interview and diary, Qin (2002) carried out a case study on the attribution tendency of eight non-English major sophomores and revealed that attribution exerted a direct influence on learning motivation. Zhang (2002) surveyed English majors' attribution in EFL learning and indicated that most participants identified themselves as unsuccessful learners and mainly attributed this failure to their deficiency of ability and effort. Based on Weiner's attribution model (1985), Li (2004) designed a questionnaire to study how non-English majors attributed their EFL learning success or failure to different factors and explore the gender or achievement-level differences in attribution.

Attempts were also made to shed light on the relationship between attribution, self-efficacy, and learning achievements (Shell et al., 1995; Zhang \& Yuan, 2004; Li \& Yu, 2008; Luo \& Chen, 2013). For instance, Zhang and Yuan (2004) explored the effects of achievement goals on non-English majors' English learning self-efficacy and attribution. It's reported that mastery goal orientation had a more positive effect on the enhancement of self-efficacy and formation of beneficial causal attributions. Luo and Chen (2013) carried out a survey to examine the relations among achievement attribution, academic self-efficacy, and EFL learning anxiety of junior students and concluded that achievement attribution could predict learning anxiety. It is also worth mentioning that Shell et al. (1995) focused on self-efficacy and attribution in writing contexts, and found grade- and achievement-level differences in these two factors. Compared with low achievers, high achievers were reported to "have higher writing self-efficacy and attribute causality for success more to internal causes (e.g., ability, effort) than to external ones (e.g., luck, task difficulty, others' help)" (Shell et al., 1995, p. 387).

\subsection{Measurements of Writing Self-Efficacy and Attribution}

Previous research has made a great contribution to the quantitative assessment of writing self-efficacy, mostly employing questionnaires or scales. Shell, Murphy and Bruning (1989) designed a scale instrument to measure American university undergraduate students' self-efficacy in writing. This instrument is composed of two subscales, namely writing task and writing component skill. The former assesses how confident the subjects are in performing writing tasks while the latter measures how confident they are in using writing skills (Sun \& Wang, 2020). On this basis, some scholars have developed various writing self-efficacy instruments in first language contexts (Zimmerman \& Bandura, 1994; Pajares \& Valiante, 1997, 1999; Pajares, 2007; Bruning et al., 2013) or second/foreign language contexts (Woodrow, 2011; Tang \& Xu, 2011; Li, 2014; Teng et al., 2018). By and large, these instruments all conform to Bandura's (1995) guidelines about how self-efficacy beliefs should be measured. For example, the differences of efficacy beliefs in level, strength, and generality should be taken into account; items should be prototypical of essay-writing and every item describes a specific writing task or skill; the instrument should be worded in terms of "I can" rather than of "I will".

The measurement of attribution in school contexts was less than that of self-efficacy, and it's mainly based on Weiner's attribution model (1985). Using a five-point Likert scale, Shell et al. (1995) asked students to rate the importance of six causes for being a good writer, including effort, ability, enjoyment, luck, task difficulty, and teacher help. To ensure a systematic description of undergraduates' success or failure attribution, Lefcourt, 
Baeyer, Ware and Cox (1979) designed the Multidimensional-Multiattributional Causality Scale. This scale consists of two subparts: one is about academic achievements and the other about affiliation (interpersonal relations). The 24 items in both subscales can be subsumed under four causes, i.e., ability, effort, context, and luck. Compared with self-efficacy, little recent attribution measurement has been made in the field of language learning or education, and EFL writing attribution assessments are even less. Although previous research has shown that writing self-efficacy was closely related to writing achievements, the relationship between writing self-efficacy, attribution and EFL writing performances among Chinese non-English majors has been less discussed. In addition, the gender and achievement-level differences in writing self-efficacy have not come to the same conclusion, which leaves room for further investigation. And the aforementioned differences in writing attribution have received scant attention. The present study tries to examine the remaining issues by answering the following three questions:

(1) What is the status quo of EFL writing self-efficacy and attribution of first-year non-English majors?

(2) What are the differences in EFL writing self-efficacy and attribution between genders?

(3) What are the differences in EFL writing self-efficacy and attribution among students at different writing levels?

\section{Method}

\subsection{Participants}

By convenience sampling, 142 first-year non-English majors from four intact classes of the College English Course at a key university in southeast China were chosen as subjects. This course is provided during the first two years at universities in China to improve students' EFL proficiency, especially in reading and writing (Sun \& Wang, 2020). The reason why the first-year non-English majors were selected was that they have received relatively inadequate writing instructions and reported lower self-efficacy beliefs (Li \& Liu, 2013; Li, 2017), which deserves attention and investigation. The participants comprised 39 males $(27.46 \%)$ and 103 females (72.54\%), and they majored in Mathematics, Music, Chemistry, and Engineering. Their average EFL learning duration was 7 years and average age 18. All participants have attended the College English Test Band Four (CET-4) and gotten their scores.

\subsection{Instruments}

\subsubsection{The Scale of EFL Writing Self-Efficacy}

The Scale of EFL Writing Self-efficacy (SEWS) in this study (see Appendix A) was adapted from the English-as-the-first-language Writing Self-efficacy Instrument (Shell et al., 1989). To measure Chinese EFL college students' writing self-efficacy, the author also referred to some related instruments designed by Chinese scholars (Tang \& Xu, 2011; Li, 2014). The SEWS (18 items) consisted of two subscales, namely skill self-efficacy scale (11 items) and task self-efficacy scale (7 items). The former is intended to measure participants' confidence in using various writing skills while the latter aims to assess their confidence in performing different writing tasks. These two subscales were centered on the skills or tasks closely involved in the CET-4 test. According to the Likert five-point scale system, participants were required to give each item a score from one to five in response to the given statements.

Exploratory factor analysis in SPSS found that KMO value registered 0.876, Bartlett's test result 1356.741, and significance level 0.000 , suggesting that the survey data were suitable for factor analysis. Three factors were extracted from the variance interpretation table, and the cumulative variance contribution rate reached $59.352 \%$. According to the factor loading matrix, the first, sixth, eighth, and tenth items in the SEWS were excluded. A second factor analysis was run on the remaining 14 items, and two common factors were extracted, namely writing skill self-efficacy ( 8 items) and writing task self-efficacy (6 items). The KMO value reached 0.895 and the cumulative variance contribution rate $57.713 \%$. The internal consistency reliability test reported that the Cronbach's alpha of the whole scale was 0.909 , and that of task-efficacy and skill-efficacy subscale registered 0.863 and 0.870 respectively, which ensured high consistency reliability and internal validity of the SEWS.

\subsubsection{The Scale of EFL Writing Attribution}

The Scale of EFL Writing Attribution (SEWA) in the present study (see Appendix B) was adapted from the achievement subscale of the Multidimensional-Multiattributional Causality Scale (Lefcourt et al., 1979). The SEWA comprised a total of 24 items, and six factors including Ability, Effort, Task difficulty, Luck, Physical \& mental condition, and External environment were extracted through factor analysis. Participants were also required to give a score for each item in the Likert five-point scale. The internal consistency reliability test was 
performed for the whole scale and six subscales, and the Cronbach's alpha of the former reached 0.942 . The Cronbach's alpha of each factor subscale registered as follows: Ability (0.735); Effort (0.711); Task difficulty (0.725); Luck (0.740); Physical \& mental condition (0.789); External environment (0.789), which showed a high internal reliability of the SEWA. To ensure and facilitate participants' interpretation, the aforementioned two scales were both translated into Chinese and revised under expert reviews.

\subsubsection{The Measurement of EFL Writing Performance}

Students' EFL writing performance was assessed by their scores in the writing part of the College English Test Band Four (CET-4), a nationwide standardized English test. In the writing section, students were allowed 30 minutes to write an essay of at least 120 words but no more than 180 words (see Yang, 2004, for more). The validity and reliability of the CET-4 writing scores were guaranteed by the rigorous selection and training of raters, and the monitoring of the whole rating process (Sun \& Wang, 2020). The total score of the writing part was 106.5 and the passing score 63.9, and students who got a score of more than 92.3 may be considered as the distinction. Using these thresholds, participants were divided into three groups, namely "high-level group" (26 persons, $92.3 \leq$ writing scores $<106.5$ ), "medium-level group" (93 persons, $63.9 \leq$ writing scores $<92.3$ ), and "low-level group" (23 persons, writing scores $<63.9)$.

\subsection{Data Collection and Processing}

The administration of the university approved the study, and all students and teachers involved gave their consent to the survey. Before the data collection, participants were informed of relevant issues, such as the instructions on how to fill in the scales and the meanings of each item. A total of 151 questionnaires were administered and collected with the assistance of College English Course teachers. Of the 151 questionnaires, 9 invalid ones were left out, and thus the return rate reached $94.04 \%$. The data obtained from the survey were entered into the social science statistical software SPSS24.0 for processing and analysis. Descriptive statistical analysis was first performed to describe the status quo of non-English majors' EFL writing self-efficacy and attribution, followed by t-test and ANOVA to examine the gender or writing-level differences.

\section{Results and Discussion}

\subsection{The Status Quo of EFL Writing Self-Efficacy and Attribution}

The descriptive characteristics (e.g., mean, standard deviation) of writing self-efficacy and attribution among first-grade non-English majors were shown in Tables 1 and 2.

Table 1 showed that the item averages of students' overall writing self-efficacy were generally at the medium level (3.3063), between 3 (I am not sure if the statement is true of me) and 4 (The statement is usually true of me), which agrees with previous research findings (Tang \& Xu, 2011; Zhang \& Guo, 2012; Li \& Liu, 2013; Sun \& Wang, 2020). The average of skill self-efficacy (3.4842) was higher than that of task self-efficacy (3.0692), which suggested that students were more confident in using writing skills than in performing writing tasks (Tang \& Xu, 2011). As Li and Liu (2013) have observed, the first-year non-English majors commonly lacked confidence in English writing and even experienced some apprehension. The participants were also found to be more self-efficacious in paragraph construction or some linguistic skill use, but less efficacious in performing a particular writing task (e.g., writing a letter or sending an e-mail in English). The result could be explained by the prevailing EFL writing teaching approach in China, which is product-oriented and examination-driven with a focus on the grammar and skills required for English exams (Ai, 2015; Sun \& Wang, 2020). Therefore, the opportunities for learners to carry out practical writing tasks may be insufficient, thus making them less confident in this respect.

According to Table 2, there existed noticeable differences in six attribution causes of EFL writing performance, among which Effort constituted the most frequently attributed (3.7606), while External Environment (2.8944) and Luck (2.9771) were less frequently attributed. In general, students were more inclined to attribute writing success or failure to internal factors such as personal efforts and ability, but external causes, such as luck and learning environment, were relatively less attributed. That to a large extent corresponds to the finding reported by Zhang (2002) and Li (2004) about Chinese students' general EFL learning attribution. Li (2004) suggested that students' attribution to internal, controllable, and unstable factors (e.g., effort) was positive and beneficial, by which they can maintain EFL learning motivation and improve outcome expectancy (see Shell et al., 1995). 
Table 1. Descriptive statistics of EFL writing self-efficacy

\begin{tabular}{llllll}
\hline & Item average & Mean & SD & Max. & Min. \\
\hline Skill self-efficacy & 3.4842 & 27.8732 & 4.6507 & 38.00 & 16.00 \\
Task self-efficacy & 3.0692 & 18.4155 & 3.8652 & 30.00 & 8.00 \\
Overall self-efficacy & 3.3063 & 46.2887 & 7.7575 & 62.00 & 29.00 \\
\hline
\end{tabular}

Note. "Mean" equals "the total scores/the number of participants", while "Item average" refers to "Mean/the number of items". The latter may roughly measure the level of writing self-efficacy and attribution. "SD" refers to "standard deviation".

Table 2. Descriptive statistics of EFL writing attribution

\begin{tabular}{llllll}
\hline & Item average & Mean & SD & Max. & Min. \\
\hline Ability & 3.2271 & 12.9084 & 2.2720 & 20.00 & 8.00 \\
Effort & 3.7606 & 15.0424 & 2.3059 & 20.00 & 9.00 \\
Task difficulty & 3.0634 & 12.2536 & 2.4909 & 18.00 & 6.00 \\
Luck & 2.9771 & 11.9084 & 2.6388 & 20.00 & 4.00 \\
Physical \& mental condition & 3.2606 & 13.0424 & 2.5761 & 19.00 & 7.00 \\
External environment & 2.8944 & 11.5776 & 2.7375 & 20.00 & 4.00 \\
\hline
\end{tabular}

\subsection{The Differences in EFL Writing Self-Efficacy and Attribution between Genders}

\subsubsection{The Differences in EFL Writing Self-Efficacy between Genders}

Table 3 indicated that the overall writing self-efficacy of boys (Mean $=46.7434)$ was slightly stronger than that of girls $($ Mean $=46.1165)$. Besides, boys' skill self-efficacy $($ Mean $=28.8462)$ was found to be stronger than girls' (Mean $=27.5049)$, but task self-efficacy level was the opposite.

Table 3. Descriptive statistics of EFL writing self-efficacy between genders

\begin{tabular}{llllll}
\hline & Gender & Number & Mean & SD & Standard error \\
\hline Overall self-efficacy & Male & 39 & 46.7434 & 8.15868 & 1.30643 \\
& Female & 103 & 46.1165 & 7.63416 & .75222 \\
Skill self-efficacy & Male & 39 & 28.8462 & 4.63135 & .74161 \\
& Female & 103 & 27.5049 & 4.62702 & .45591 \\
Task self-efficacy & Male & 39 & 17.8974 & 3.98547 & .63819 \\
& Female & 103 & 18.6117 & 3.82005 & .37640 \\
\hline
\end{tabular}

Independent sample t-test results (see Table 4) suggested no significant difference in overall writing self-efficacy $(p=0.669>0.05)$, skill self-efficacy $(p=0.125>0.05)$ and task self-efficacy $(p=0.327>0.05)$ between boys and girls. That is to say, gender exerted no significant influence on EFL writing self-efficacy, which tallies with some research findings (Shell et al., 1995; Pajares \& Valiante, 1999; Tang \& Xu, 2011). However, Pajares and Johnson (1996) found that girls reported lower writing self-efficacy, while other studies argued that girls reported stronger writing self-efficacy and were rated better writers by their teachers (Pajares et al., 1999; Pajares \& Valiante, 2001; Pajares, Johnson, \& Usher, 2007). This inconsistency may be due in part to the fact that boys and girls may use a different "metric" or gauge when providing confidence judgments, and girls tend to be more modest and discreet (see Pajares, 2003, for more). It could also be explained by the difference or diversity of every study (e.g., environment, conditions, sampling). Further investigation should be conducted to explore the gender differences in writing self-efficacy.

Table 4. Independent sample t-test of EFL writing self-efficacy between genders

\begin{tabular}{lllllll}
\hline & Levene & $\mathrm{t}$ & $\mathrm{df}$ & $\mathrm{sig}$ & $\mathrm{MD}$ & Standard error \\
\hline Overall self-efficacy & .704 & .429 & 140 & .669 & .6271 & 1.46276 \\
Skill self-efficacy & .839 & 1.541 & 140 & .125 & 1.3413 & .87017 \\
Task self-efficacy & .648 & -.983 & 140 & .327 & -.7142 & .72680 \\
\hline
\end{tabular}

\subsubsection{The Differences in EFL Writing Attribution between Genders}

As was shown in Table 5, no significant difference was found between males and females in writing attribution causes, with the only exception of Luck $(\mathrm{p}<0.05)$. Compared with boys $($ Mean $=11.1282)$, girls $($ Mean $=$ 
12.2039) were more likely to attribute their writing performance to luck. The result also echoed Li's findings (2004) that both boys and girls tended to attribute EFL learning outcomes to internal factors (e.g., effort, physical $\&$ mental condition, ability) rather than to external ones, and most of them attributed to effort.

Table 5. Independent sample t-test of writing attribution between genders

\begin{tabular}{llllll}
\hline & Gender & Mean & SD & Levene & $\mathrm{t}$ \\
\hline Ability & Male & 12.8205 & 2.26961 & .822 & -.283 \\
& Female & 12.9417 & 2.28304 & & \\
Effort & Male & 15.3846 & 2.48803 & .500 & 1.089 \\
Task difficulty & Female & 14.9126 & 2.23215 & & \\
\multirow{2}{*}{ Luck } & Male & 12.3846 & 2.69127 & .448 & .385 \\
& Female & 12.2040 & 2.42276 & & \\
Physical \& mental condition & Male & 11.1282 & 2.51500 & .666 & $-2.197^{*}$ \\
& Female & 12.2039 & 2.63595 & & \\
External environment & Male & 13.0769 & 2.57911 & .780 & .098 \\
& Female & 13.0291 & 2.58751 & & \\
& Male & 11.0000 & 2.57519 & .310 & -1.555 \\
& Female & 11.7961 & 2.77722 & & \\
\hline
\end{tabular}

Note. * represents "p $<0.05$ ", ** represents " $\mathrm{p}<0.01$ ”, two-tailed.

\subsection{The Differences in EFL Writing Self-Efficacy and Attribution in Terms of Writing Levels}

\subsubsection{The Differences in EFL Writing Self-Efficacy Between High-Level and Low-Level Groups}

Independent sample t-test (see Table 6) noted a significant difference between high-level and low-level groups in overall writing self-efficacy and skill self-efficacy $(\mathrm{p}<0.01)$, which revealed that low-level students were relatively less self-efficacious in EFL writing and linguistic skill use. In terms of task self-efficacy, the difference between the high-level and low-level groups was not significantly marked $(p>0.05)$. A tentative conclusion could thus be drawn that there was no significant correlation between writing task self-efficacy and writing level. That is, irrespective of writing level, first-year college students generally lack confidence in completing practical writing tasks, and have negative self-evaluation of their writing competence ( $\mathrm{Li} \& \mathrm{Liu}, 2013$ ). The possible reasons have been discussed in section 4.1.

Table 6. Independent sample t-test of writing self-efficacy between high-level and low-level groups

\begin{tabular}{llllll}
\hline & Group & Mean & SD & Levene & t \\
\hline Overall self-efficacy & H & 49.8077 & 4.02014 & .120 & $3.472^{* *}$ \\
& L & 43.8846 & 5.90137 & & \\
Skill self-efficacy & H & 29.8462 & 2.49307 & .221 & $3.109 * *$ \\
& L & 25.3846 & 3.81656 & & \\
Task self-efficacy & H & 20.9615 & 2.69044 & .760 & 1.893 \\
& L & 18.5000 & 2.86007 & & \\
\hline
\end{tabular}

Note. H represents "high-level group", M represents "medium-level group", L represents "low-level group".

\subsubsection{The Differences in EFL Writing Attribution of Students at Three Writing Levels}

According to one-way ANOVA results in Table 7, four attribution causes, i.e., Ability, Effort, Task difficulty, and Physical \& mental conditions were relatively obvious. And LSD-test findings suggested that two attribution causes, namely Task difficulty $(\mathrm{p}<0.05)$ and Physical \& mental condition $(\mathrm{p}<0.05)$ significantly differed between high-level and low-level groups. The results indicated that the majority of students attributed writing outcomes to two internal factors Effort and Ability regardless of writing level, but low-level students were also inclined to attribute externally (e.g., task difficulty). Similar findings were reported by previous research (Shell et al., 1995; Zhang, 2002; Qin, 2002; Li, 2004). For example, Shell et al. (1995) proposed that compared with low achievers, high achievers tended to have higher writing self-efficacy, and attribute causality for success more to internal causes (ability or effort) relatively to external ones (luck, task difficulty, or others' help).

From the perspective of Weiner's Attribution Theory (1985), high-level students attributing writing achievements to ability possess strong self-beliefs in their writing competence, and those favoring effort attribution may consider hard work as the essential ingredient for their success. These positive attributions will be conducive to 
EFL learning. However, low-level students sometimes attribute negatively (e.g., ability, task difficulty, external environment). They may presume that they are always incapable of performing EFL writing tasks well, thereby possibly developing a sense of "learned helplessness" (Zhang, 2002, p. 59). Moreover, some students may fail to properly make self-determination and self-evaluation, and therefore have low outcome expectancy and dismiss their failure in EFL writing (Zhang, 2005). Consequently, measures should be taken by both teachers and students, which will be discussed in the following part.

Table 7. One-way ANOVA of EFL writing attribution of students at different writing levels (only obvious causes presented)

\begin{tabular}{|c|c|c|c|c|c|c|c|c|c|}
\hline & \multicolumn{2}{|c|}{$\mathrm{H}(\mathrm{N}=26)$} & \multicolumn{2}{|c|}{$\mathrm{M}(\mathrm{N}=93)$} & \multicolumn{2}{|c|}{$\mathrm{L}(\mathrm{N}=23)$} & \multirow[t]{2}{*}{$\mathrm{F}$} & \multirow{2}{*}{$\begin{array}{l}\text { Multiple } \\
\text { comparisons } \\
\text { LSD }\end{array}$} & \multirow[t]{2}{*}{$\mathrm{MD}$} \\
\hline & Mean & $\mathrm{SD}$ & Mean & SD & Mean & SD & & & \\
\hline \multirow[t]{3}{*}{ Ability } & 14.8261 & 1.73338 & 12.9140 & 1.95968 & 12.7308 & 2.26940 & 10.872 & $\mathrm{H}>\mathrm{M}$ & 1.9121 \\
\hline & & & & & & & & $\mathrm{H}>\mathrm{L}$ & 2.0953 \\
\hline & & & & & & & & $M>L$ & 0.1832 \\
\hline \multirow[t]{3}{*}{ Effort } & 16.4615 & 1.55514 & 15.0645 & 1.76196 & 14.2174 & 1.75697 & 11.367 & $\mathrm{H}>\mathrm{M}$ & 1.3970 \\
\hline & & & & & & & & $\mathrm{H}>\mathrm{L}$ & 2.2441 \\
\hline & & & & & & & & $\mathrm{M}>\mathrm{L}$ & 0.8471 \\
\hline \multirow[t]{3}{*}{ Task difficulty } & 8.6538 & 1.62339 & 10.0538 & 1.91314 & 12.2174 & 1.75697 & 25.519 & $\mathrm{H}>\mathrm{M}$ & -1.4000 \\
\hline & & & & & & & & $\mathrm{H}>\mathrm{L}$ & $-3.5636^{*}$ \\
\hline & & & & & & & & $\mathrm{M}>\mathrm{L}$ & -2.1636 \\
\hline \multirow{3}{*}{$\begin{array}{l}\text { Physical \& } \\
\text { mental condition }\end{array}$} & 6.3462 & 1.87494 & 8.6667 & 2.07120 & 11.0870 & 2.06514 & 27.911 & $\mathrm{H}>\mathrm{M}$ & -2.3205 \\
\hline & & & & & & & & $\mathrm{H}>\mathrm{L}$ & $-4.7408 *$ \\
\hline & & & & & & & & $\mathrm{M}>\mathrm{L}$ & -2.4203 \\
\hline
\end{tabular}

\subsection{Pedagogical Implications}

This study also has some pedagogical implications, and it can provide suggestions for both teachers and students. On the one hand, the present study suggested a positive relationship between writing self-efficacy, attribution, and writing proficiency, which was supported by previous research (Shell et al., 1995; Pajares, 2003; Zhang, 2005; Tang \& Xu, 2011; Li \& Liu, 2013; Sun \& Wang, 2020). Therefore, EFL writing teachers are first recommended to realize the importance of motivation or affect constructs in writing instruction. As Bandura (1986) has highlighted, educational practices should be gauged not only by the skills and knowledge they impart for present use but also by what they do to children's beliefs about their capabilities, which affects how they approach the future. Pajares (2003) also proposed that novice teachers should be taught to assess both competence and the beliefs that accompany competence as part of writing evaluations. Furthermore, teachers are encouraged to help students develop strong self-efficacy in EFL writing. For example, they are expected to provide students with more practical writing tasks and related skills or strategies training, and "chaperone these efforts with trust, support and encouragement" (Mills \& Clyde, 1991), thereby improving students' task and skill self-efficacy. Besides, the product approach should be partially superseded by the process approach and summative evaluation by formative evaluation in writing teaching, to help students overcome psychological blockages with positive emotions (see Zhang, 2005, for more). Given the low self-beliefs and negative attribution of some low-achievers, teachers should properly offer them constructive feedback, to help them maintain motivation and avoid "learned helplessness" (Zhang, 2002; Li, 2004). For instance, teachers can praise these students as "hard-working" rather than "clever" for their writing progress, to promote their positive attribution.

On the other hand, students should realize the underlying impetus of self-efficacy and attribution, and try to develop positive self-beliefs in EFL writing. They are expected to attribute writing outcomes to internal and controllable factors (e.g., effort) and dismiss negative beliefs (e.g., my poor writing performance is largely due to unchangeable deficiency in ability). In addition, they can seek assistance and guidance from teachers and peers if necessary, because writing turns out to be not only a psychological or cognitive activity but also an act of social interaction (Bandura, 1986; Hayes, 2000). Therefore, they are encouraged to communicate with others about their writing problems. Furthermore, writing self-efficacy was found to be changeable and developable, and this development would be impacted by individual differences (Schunk \& Swartzs, 1993). Consequently, the individual differences, especially developmental differences, in writing self-beliefs should be considered and employed by both students and teachers. 
Confidence in writing ability plays a positive role in improving actual output, not because it develops one's writing competence, but contributes to the cultivation or maintenance of motivational factors such as interest, effort, and will. As Beach (1989) pointed out, students' self-perceptions of their writing competence offered a particularly promising avenue of research for informing writing instruction. Therefore, enhancing students' self-beliefs proves an effective measure to improve their writing performance, and it also provides innovative ideas for writing teaching reform in the future.

\section{Conclusion}

The current study examines the relationship between writing self-efficacy, attribution and writing outcomes of Chinese college students in an EFL learning context. The main findings are as follows: (1) first-grade non-English majors' writing self-efficacy is generally at the medium level, and their skill self-efficacy is stronger than task self-efficacy. Students tend to attribute their writing outcomes to internal causes, among which effort ranks the first; (2) gender exerts no significant impact on English writing self-efficacy; only the attribution cause Luck significantly differs between boys and girls; (3) students at a higher writing level possess stronger writing self-efficacy and skill self-efficacy. Regardless of writing level, students tend to attribute their writing success or failure to internal factors such as ability and effort, while those at a low level are also inclined to attribute externally. This study also has the following limitations: (1) the data of the study were collected from only one university by convenience sampling, which may fail to well represent the status quo of Chinese EFL learners. Future research is thus expected to survey Chinese students from different universities in various regions; (2) this study followed the quantitative method of existing empirical research on writing self-efficacy, and conditions being constrained, the researcher failed to obtain specific data of writing scores. Consequently, it is hard for this study to investigate how writing self-efficacy and attribution relate to or predict writing scores. Future research can further track the predictive or mediating effect of motivational factors on writing performance; (3) there was still some room for improvement in scale design, variable control, data collection and analysis, which may concern the accuracy and credibility of results.

\section{References}

Ai, B. (2015). A study of the EFL writing of Chinese learners: A critical narrative. Changing English, 22(3), 294-306. https://doi.org/10.1080/1358684X.2015.1056091

Anastasiou, D., \& Michail, D. (2013). Exploring discourse between self-efficacy and writing performance among low-literate adult students. Learning Disabilities: A Contemporary Journal, 11(1), 53-87. Retrieved from http://web.a.ebscohost.com

Bandura, A. (1986). Social foundations of thought and action: A social cognitive theory. Englewood Cliffs, NJ: Prentice-Hall.

Bandura, A. (1995). Guide for constructing self-efficacy scales. Available from Frank Pajares, Division of Educational Studies, Emory University, Atlanta, GA, 30322.

Bandura, A., \& Schunk, D. H. (1981). Cultivating competence, self-efficacy, and intrinsic interest through proximal self-motivation. Journal of Personality and Social Psychology, 41(3), 586-598. https://doi.org/10.1037/0022-3514.41.3.586

Beach, R. (1989). Showing students how to assess: Demonstrating techniques for response in the writing conference. In C. M. Anson (Ed.), Writing and response (pp. 127-148). Urbana, IL: NCTE.

Bruning, R., Dempsey, M., Kauffman, D. F., McKim, C., \& Zumbrunn, S. (2013). Examining dimensions of self-efficacy for writing. Journal of Educational Psychology, 105(1), 25-38. https://doi.org/10.1037/a0029692

Bruning, R., \& Horn, C. (2000). Developing motivation to write. Educational Psychologist, 35(1), 25-37. https://doi.org/10.1207/S15326985EP3501_4

Csizér, K., \& Tankó, G. (2015). English majors' self-regulatory control strategy use in academic writing and its relation to L2 motivation. Applied Linguistics, 38(3), 386-404. https://doi.org/10.1093/applin/amv033

Daniels, S., Mccurdy, M., Whitsitt, L., Skinner, C. H., Schwartz-Micheaux, J., \& White, J. (2019). Evaluating the effects of a writing self-efficacy intervention on writing quantity in middle school students. Reading \& Writing Quarterly, 36(1), 48-64, https://doi.org/10.1080/10573569.2019.1618226

Faigley, L., Cherry, R. D., Jolliffe, D. A., \& Skinner, A. M. (1985). Assessing writers'knowledge and processes of composing. Norwood, NJ: Ablex. 
Graham, S., \& Harris, K. R. (1997). It can be taught, but it does not develop naturally: Myths and realities in writing instruction. School Psychology Review, 26(3), 414-424. https://doi.org/10.1080/02796015.1997.12085875

Han, J., \& Hiver, P. (2018). Genre-based L2 writing instruction and writing-specific psychological factors: The dynamics of change. Journal of Second Language Writing, 40, 44-59. https://doi.org/10.1016/j.jslw.2018.03.001

Hayes, J. R. (2000). A new framework for understanding cognition and affect in writing. In R. Indrisano \& J. R. Squire (Eds.), Perspectives on writing: Research, theory, and practice (pp. 6-44). Newark, DE: International Reading Association.

Heider, F. (1958). The psychology of interpersonal relations. New York: Wiley. https://doi.org/10.1037/10628-000

Kellogg, R. (2008). Training writing skills: A cognitive developmental perspective. Journal of Writing Research, 1(1), 1-26. https://doi.org/10.17239/jowr-2008.01.01.1

Lefcourt, H. M., Von Baeyer, C. L., Ware, E. E., \& Cox, D. J. (1979). The multidimensional-multiattributional causality scale: The development of a goal specific locus of control scale. Canadian Journal of Behavioral Science, 11(4), 286-304. https://doi.org/10.1037/h0081598

Li, B. B., \& Xu, J. F. (2014). Achievement goals orientation and autonomous English learning ability: The mediating role of self-efficacy. Foreign Languages in China, 11(3), 59-68.

Li, C. Z. (2004). A survey study on the attribution of non-English majors in EFL learning. Foreign Language World, 6, 41-45.

Li, H. (2014). Construction of EFL writing self-efficacy scale for Chinese college students. Journal of Beijing International Studies University, 36(12), 70-76.

Li, H. (2017). The effects of English writing self-efficacy on non-English majors' writing performance. Foreign Language Learning Theory and Practice, 3, 57-63.

Li, H., \& Liu, R. D. (2013). College students' EFL writing anxiety and self-efficacy and their prediction on students' writing performance. Foreign Language Research, 2, 48-54.

Li, K., \& Yu, L. M. (2008). A survey study on the relationship between EFL learning motivation, self-efficacy, attribution, and self-regulation among college students. Foreign Language Learning Theory and Practice, 2, $1-5$.

Luo, R., \& Chen, J. J. (2013). Achievement attribution, academic self-efficacy and foreign language anxiety. Chinese Journal of Clinical Psychology, 21(2), 300-305.

McCutchen, D. (1996). A capacity theory of writing: Working memory in composition. Educational Psychology Review, 8(3), 299-325. https://doi.org/10.1007/BF01464076

Mills, H., \& Clyde, J. A. (1991). Children's success as readers and writers: It's the teacher's beliefs that make the difference. Young Children, 46(2), 54-59. Retrieved from http://web.a.ebscohost.com

Pajares, F. (2003). Self-efficacy beliefs, motivation, and achievement in writing: A review of the literature. Reading \& Writing Quarterly, 19(2), 139-158. https://doi.org/10.1080/10573560308222

Pajares, F. (2007). Empirical properties of a scale to assess writing self-efficacy in school contexts. Measurement and Evaluation in Counselling and Development, 39(4), 239-249. https://doi.org/10.1080/07481756.2007.11909801

Pajares, F., Britner, S. L., \& Valiante, G. (2000). Relationship between achievement goals and self-beliefs of middle school students in writing and science. Contemporary Educational Psychology, 25(4), 406-422. https://doi.org/10.1006/ceps.1999.1027

Pajares, F., \& Johnson, M. J. (1996). Self-efficacy beliefs in the writing of high school students: A path analysis. $\begin{array}{llll}\text { Psychology in } & \text { Schools, }\end{array}$ https://doi.org/10.1002/(SICI)1520-6807(199604)33:2<163::AID-PITS10>3.0.CO;2-C

Pajares, F., Johnson, M. J., \& Usher, E. L. (2007). Sources of writing self-efficacy beliefs of elementary, middle, and high school students. Research in the Teaching of English, 42(1), 104-120. Retrieved from http://www.jstor.org/stable/40171749

Pajares, F., Miller, M. D., \& Johnson, M. J. (1999). Gender differences in writing self-beliefs of elementary 
school students. Journal of Educational Psychology, 91(1), 50-61. https://doi.org/10.1037/0022-0663.91.1.50

Pajares, F., \& Valiante, G. (1999). Grade level and gender differences in the writing self-beliefs of middle school students. Contemporary Educational Psychology, 24(4), 390-405. https://doi.org/10.1006/ceps.1998.0995

Pajares, F., \& Valiante, G. (2001). Gender differences in writing motivation and achievement of middle school students: A function of gender orientation? Contemporary Educational Psychology, 26(3), 366-381. https://doi.org/10.1006/ceps.2000.1069

Qin, X. Q. (2002). Causal attribution and its conceptions by EFL learners at the tertiary level: A case study. Modern Foreign Languages, 25(1), 71-78.

Qiu, X., \& Lee, M.-K. (2020). Regulated learning and self-efficacy beliefs in peer collaborative writing: An exploratory study of L2 learners' written products, task discussions, and self-reports, System, 93, 1-45. https://doi.org/10.1016/j.system.2020.102312

Sabti, A. A., Md Rashid, S., Nimehchisalem, V., \& Darmi, R. (2019). The impact of writing anxiety, writing achievement motivation, and writing self-efficacy on writing performance: A correlational study of Iraqi tertiary EFL learners. SAGE Open, 9(4), 1-13. https://doi.org/10.1177/2158244019894289

Schunk, D. H., \& Swartz, C. W. (1993). Goals and progress feedback: Effects on self-efficacy and writing $\begin{array}{lllll}\text { achievement. } \quad \text { Contemporary } & \text { Educational }\end{array}$ https://doi.org/10.1006/ceps.1993.1024

Shell, D. F., Colvin, C., \& Bruning, R. H. (1995). Self-efficacy, attribution, and outcome expectancy mechanisms in reading and writing achievement: Grade-level and achievement-level differences. Journal of Educational Psychology, 87(3), 386-398. https://doi.org/10.1037/0022-0663.87.3.386

Shell, D. F., Murphy, C. C., \& Bruning, R. H. (1989). Self-efficacy and outcome expectancy mechanisms in reading and writing achievement. Journal of Educational Psychology, 81(1), 91-100. https://doi.org/10.1037/0022-0663.81.1.91

Sun, T., \& Wang, C. (2020). College students' writing self-efficacy and writing self-regulated learning strategies in learning English as a foreign language. System, 90, 1-17. https://doi.org/10.1016/j.system.2020.102221

Tang, F., \& Xu, J. F. (2011). A survey study on Chinese college students' English writing self-efficacy. Foreign Language World, 6, 22-29.

Teng, L. S., Sun, P. P., \& Xu, L. (2018). Conceptualizing writing self-efficacy in English as a foreign language context: Scale validation through structural equation modeling. TESOL Quarterly, 52(4), 911-942. https://doi.org/10.1002/tesq.432

Teng, L. S., \& Zhang, L. J. (2020). Empowering learners in the second/foreign language classroom: Can self-regulated learning strategies-based writing instruction make a difference? Journal of Second Language Writing, 48, 1-16. https://doi.org/10.1016/j.jslw.2019.100701

Weiner, B. (1972). Attribution theory, achievement motivation, and the educational process. Review of Educational Research, 42(2), 203-215. https://doi.org/10.3102/00346543042002203

Weiner, B. (1979). A theory of motivation for some classroom experiences. Journal of Educational Psychology, 71(1), 3-25. https://doi.org/10.1037/0022-0663.71.1.3

Weiner, B. (1985). An attributional theory of achievement motivation and emotion. Psychological Review, 92(4), 548-573. https://doi.org/10.1037/0033-295X.92.4.548

Walker, C. O., Greene, B. A., \& Mansell, R. A. (2006). Identification with academics, intrinsic/extrinsic motivation, and self-efficacy as predictors of cognitive engagement. Learning and Individual Differences, 16(1), 1-12. https://doi.org/10.1016/j.lindif.2005.06.004

Wen, Q., \& Johnson, R. K. (1997). L2 learner variables and English achievement: A study of tertiary-level English majors in China. Applied Linguistics, 18(1), 27-48. https://doi.org/10.1093/applin/18.1.27

Woodrow, L. (2011). College English writing affect: Self-efficacy and anxiety. System, 39, 510-522. https://doi.org/10.1016/j.system.2011.10.017

Yang, H. Z. (2004). An analysis of the English proficiency of the Chinese students as reflected in the National CET Test. Foreign Languages in China, 1(1), 56-60.

Zhang, Q. Z. (2002). Survey studies on students' attribution in English learning. Foreign Languages and Their 
Teaching, 7, 57-60.

Zhang, W. J., \& Yuan, L. X. (2004). The effects of achievement goals on non-English majors' English learning. Technology Enhanced Foreign Language Education, 5, 21-25.

Zhang, X. L. (2005). Psychological blockage and its adaptation in English writing: The cultivation of positive emotions from the process approach. Foreign Languages and Their Teaching, 5, 24-27.

Zhang, Y., \& Guo, H. (2012). A study of English writing and domain-specific motivation and self-efficacy of Chines EFL learners. Pan-Pacific Association of Applied Linguistics, 16(2), 101-121. Retrieved from http://web.a.ebscohost.com

Zimmerman, B. J., \& Bandura, A. (1994). Impact of self-regulatory influences on development of writing proficiency. American Educational Research Journal, 31(4), 845-862. https://doi.org/10.3102/00028312031004845

Zimmerman, B. J., \& Kitsantas, A. (1999). Acquiring writing revision skill: Shifting from process to outcome self-regulatory goals. Journal of Educational Psychology, 91(2), 241-250. https://doi.org/10.1037/0022-0663.91.2.241

\section{Appendix A}

\section{The Scale of EFL Writing Self-efficacy (Adapted from Shell et al., 1989)}

Gender: Age:

Grade:

Class:

Major:

The time of English learning:

The scores of CET-4 writing part:
A. $\quad 92.3 \leq \mathrm{X}<106.5$
B. $63.9 \leq \mathrm{X}<92.3$
C. $X<63.9$

\begin{tabular}{|c|c|c|c|c|c|}
\hline \multicolumn{6}{|l|}{ Please tick the number accurately representing your capabilities. } \\
\hline $\begin{array}{l}1=\text { The statement is never true of me.（该表述完全不符合我） } \\
2=\text { The statement is usually not true of me.（该表述多数情况下不符合我） } \\
3=\text { I am not sure if the statement is true of me.（不确定该表述是否符合我） } \\
4=\text { The statement is usually true of me.（该表述多数情况下符合我） } \\
5=\text { The statement is completely true of me.（该表述完全符合我） }\end{array}$ & & & & & \\
\hline 1. I can correctly spell all words in a one-page passage. & 1 & 2 & 3 & 4 & 5 \\
\hline I can perform an English writing task according to the requirements specified. & 1 & 2 & 3 & 4 & 5 \\
\hline $\begin{array}{l}\text { 3. I can write or reply to in English congratulatory letters, birthday cards, thank-you letters, } \\
\text { invitations, complaints, notes, notices, etc. }\end{array}$ & 1 & 2 & 3 & 4 & 5 \\
\hline 4. I can write in English a persuasive argumentative essay to clearly express an opinion. & 1 & 2 & 3 & 4 & 5 \\
\hline I can write or reply in English personal or company letters, emails, etc. & 1 & 2 & 3 & 4 & 5 \\
\hline I can correctly use parts of speech (e.g., nouns, verbs, adjectives). & 1 & 2 & 3 & 4 & 5 \\
\hline I can write in English a descriptive essay with vivid details. & 1 & 2 & 3 & 4 & 5 \\
\hline I can write a summary of a long English essay and cover its main ideas. & 1 & 2 & 3 & 4 & 5 \\
\hline I can write in English a well-organized expository essay. & 1 & 2 & 3 & 4 & 5 \\
\hline I can write a simple sentence with proper punctuation and grammatical structure. & 1 & 2 & 3 & 4 & 5 \\
\hline 11. I can correctly use verb tenses in a one-page passage. & 1 & 2 & 3 & 4 & 5 \\
\hline $\begin{array}{l}\text { 12. I can write an English essay with a good overall organization (e.g., ideas in order, effective } \\
\text { transitions, etc.). }\end{array}$ & 1 & 2 & 3 & 4 & 5 \\
\hline 13. I can correctly use the singular and plural forms in a one-page passage. & 1 & 2 & 3 & 4 & 5 \\
\hline $\begin{array}{l}\text { 14. I can write compound and complex sentences with proper punctuation and grammatical } \\
\text { structure. }\end{array}$ & 1 & 2 & 3 & 4 & 5 \\
\hline 15. I can organize sentences into a paragraph to clearly express a theme. & 1 & 2 & 3 & 4 & 5 \\
\hline I can write in English a narrative essay with some plots and character descriptions. & 1 & 2 & 3 & 4 & 5 \\
\hline I can correctly punctuate a one-page passage. & 1 & 2 & 3 & 4 & 5 \\
\hline I can write topic sentences that integrate different kinds of information. & 1 & 2 & 3 & 4 & 5 \\
\hline
\end{tabular}




\section{Appendix B}

\section{The Scale of EFL Writing Attribution (Adapted from Lefcourt et al., 1979)}

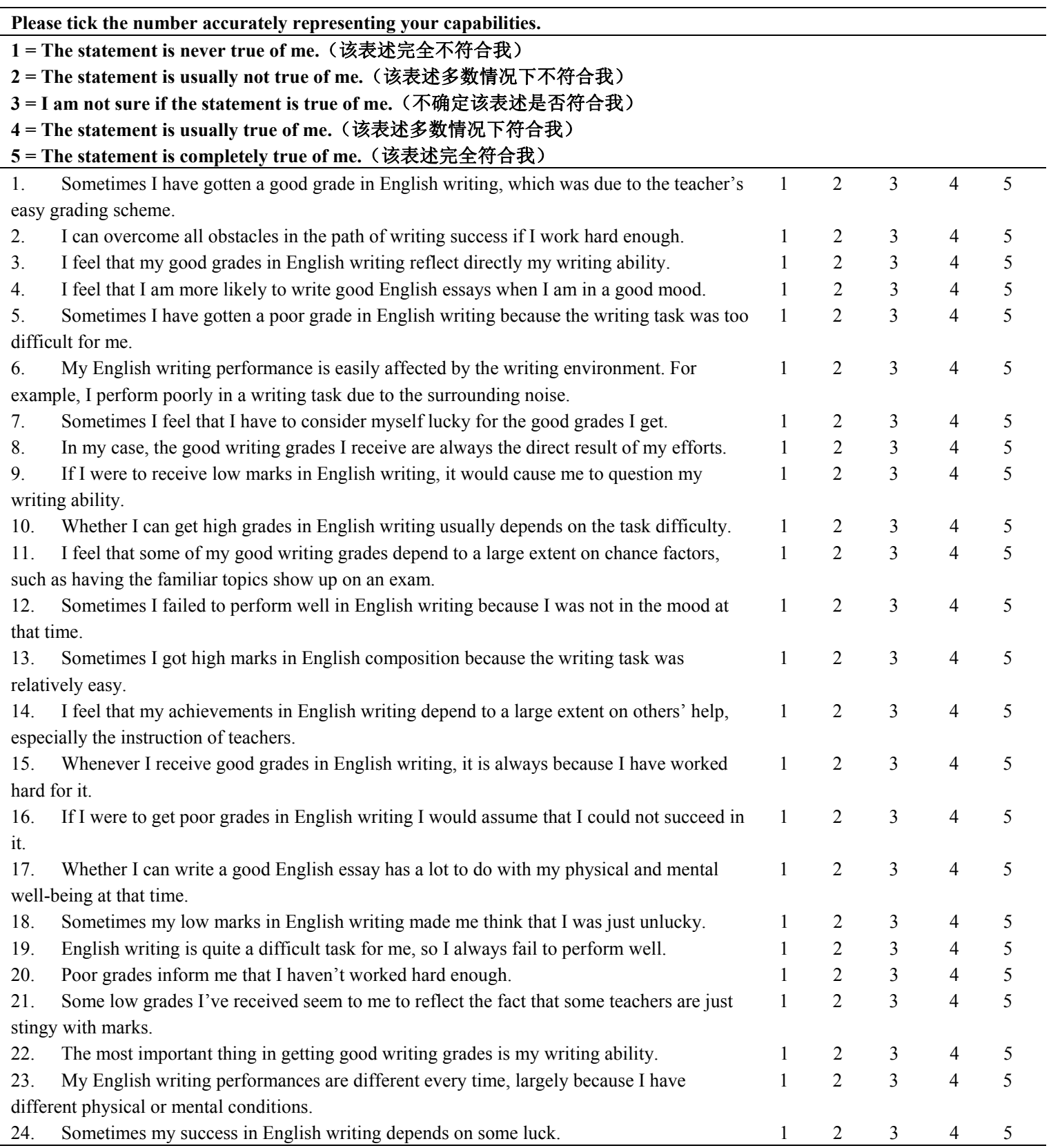

\section{Copyrights}

Copyright for this article is retained by the author, with first publication rights granted to the journal.

This is an open-access article distributed under the terms and conditions of the Creative Commons Attribution license (http://creativecommons.org/licenses/by/4.0/). 